\title{
Structural Conditions for Interdisciplinarity
}

\author{
LAR S ENGWALL \\ Department of Business Studies, Uppsala University, Sweden. \\ Email: Lars.Engwall@fek.uu.se
}

\begin{abstract}
Analysing structural conditions for interdisciplinarity, this paper focuses on the characteristics of four factors in the organization of the sciences: disciplines, institutions, rewards and funding. It is argued that interdisciplinarity is less likely to involve disciplines that are strongly integrated, i.e. where task uncertainty is low and the dependence among researchers is high. Likewise, it is claimed that interdisciplinarity is likely to be hampered by strong departmental organization structures. Interdisciplinarity is also considered to become less likely as quality control is specifically discipline oriented and also when funding is concentrated and in the hands of scientific elites. In contrast, interdisciplinary research may be found in research environments with weakly integrated disciplines in institutions with weak or no departmental structures, and where disciplinary reward systems are weak in systems with a variety of funding.
\end{abstract}

\section{Introduction}

With the passage of time, academic disciplines have developed, generally with increasing specialization in sub-disciplines. At the same time, it is evident that many problems in present-day society, such as those associated with climate change, energy shortage and population growth, require expertise from many different fields for their solution. It has also been noted that scientific discoveries tend to be made at the borderlines of traditional disciplines. These circumstances have stimulated interdisciplinary research as well as research on interdisciplinarity. ${ }^{1}$ According to a committee set up by the Swedish National Academy of Science, such academic work can be defined as: ${ }^{2}$

a mode of research by teams or individuals that integrates information, data, techniques, tools, perspectives, concepts, and/or theories from two or more disciplines or bodies of specialized knowledge to advance fundamental understanding or to solve problems whose solutions are beyond the scope of a single discipline or field of research practice. 


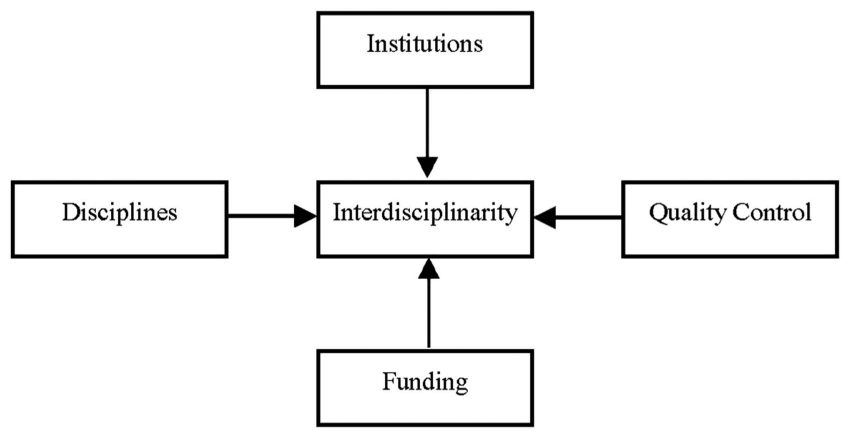

Figure 1. Four structural conditions influencing interdisciplinarity.

However, although there are strong voices in favour of interdisciplinarity, and efforts to work in an interdisciplinary mode, it should be acknowledged that there are a number of factors that may impede such research.

Against the above backdrop this paper will discuss how structural conditions may hamper interdisciplinary research. As shown in Figure 1, four such conditions appear particularly worth focusing on, namely (1) disciplines, (2) institutions, (3) quality control, and (4) funding. As for disciplines, the degree of integration within a specific scientific field is important for the readiness of scholars to take part in interdisciplinary research. Likewise, it is central how institutions are structured; that is, whether the research is organized towards solving specific tasks or according to disciplines. Furthermore, quality control is significant in that it signals to researchers what kind of research is valued. Finally, the principles for funding are essential, particularly the concentration of and the elite control over research resources. These four structural conditions will be discussed in separate sections below. At the end, the paper will summarize the findings and discuss how interdisciplinarity may be facilitated.

\section{Disciplines}

An obvious prerequisite for interdisciplinarity is the existence of disciplines, i.e. that there are scientific fields defined and protected by representatives of these fields. Within these, there are to varying extents specific rules of order determining proper behaviour. In the words of the seventh edition of the Concise Oxford Dictionary, a discipline is a 'branch of instruction and learning; mental and moral training, adversity as effecting this; systems of rules for conduct; behaviour according to established rules'. ${ }^{3}$ This means that academic disciplines are characterized by a certain degree of control, i.e. that rules are followed, and that researchers within a specific discipline are following in the footsteps of their predecessors. With a formulation attributed to Bernard of Chartres in the twelfth century, later made widely known by Robert K. Merton: 'Standing on the shoulders of giants'.

However, although quality control is a basic principle in academic work (see further below), the latter is also tasked with being innovative. A prerequisite for this may 


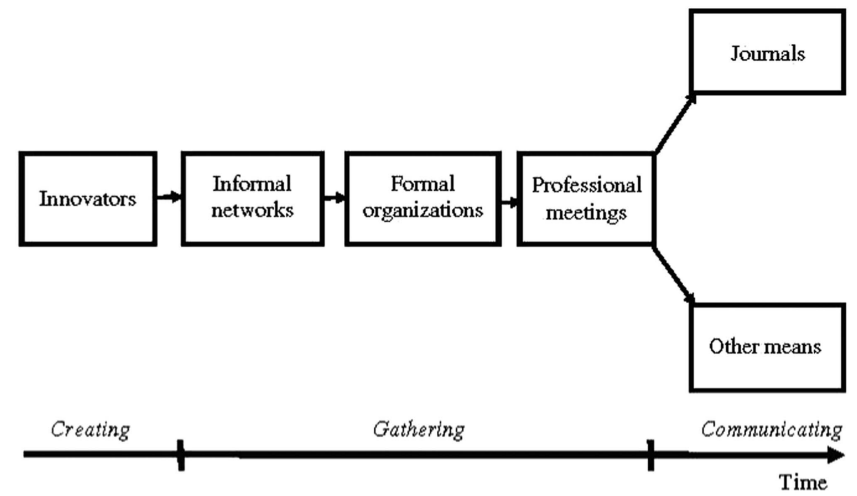

Figure 2. The development of scientific fields.

be that old rules and methods are not followed but are in fact violated. According to the seminal work by Thomas S. Kuhn, knowledge production can thus generally be characterized as normal science within paradigms, which on certain occasions is questioned by the emergence of revolutionary science. ${ }^{5}$ Since the publication of his 1962 book, Kuhn's ideas have received considerable attention but have also been challenged. ${ }^{6}$ This has become even more natural as the world of scientists has grown considerably. While the empirical basis for Kuhn's book was developments in a world of few scientists, the present-day world is crowded with scientists, in whom various stakeholders place high expectations. ${ }^{7}$ Nevertheless, Kuhn's basic idea that the established scholars are defending themselves against 'the young Turks' is still highly relevant. However, there is evidence that new ideas and new approaches are emerging simultaneously around the world, and that academic entrepreneurs eventually find their way forward through international cooperation. In this way, new approaches will develop not through revolutions but rather in a way that the political scientist Charles E. Lindblom has labelled a process of 'muddling through'. ${ }^{8}$ The development of new disciplines can therefore be summarized as in Figure 2: innovators from different countries find like-minded colleagues and gather in informal networks, which eventually turn into more and more formal organizations with professional meetings, journals and other means of communication. ${ }^{9}$

Obviously new fields will offer their members more degrees of freedom. However, over time such fields will also develop their disciplinary rules as the former outsiders turn into insiders protecting their field, and so on.

The conditions of different scientific fields, be they young or old, are basically dependent on their degree of integration, which in turn varies. Following the British sociologist Richard Whitley, we can identify two major variables determining the integration of scientific fields: task uncertainty and the dependence among researchers. ${ }^{10}$ As shown in Figure 3, in fields where the dependence among researchers is high and task uncertainty is low, integration is high. In such fields peers have strong control over the field, and researchers know what they are supposed to do and how to do it. At the other extreme, where the dependence among researchers is low and task uncertainty is high, the integration is low. Researchers in such fields have relatively 
Dependence among researchers

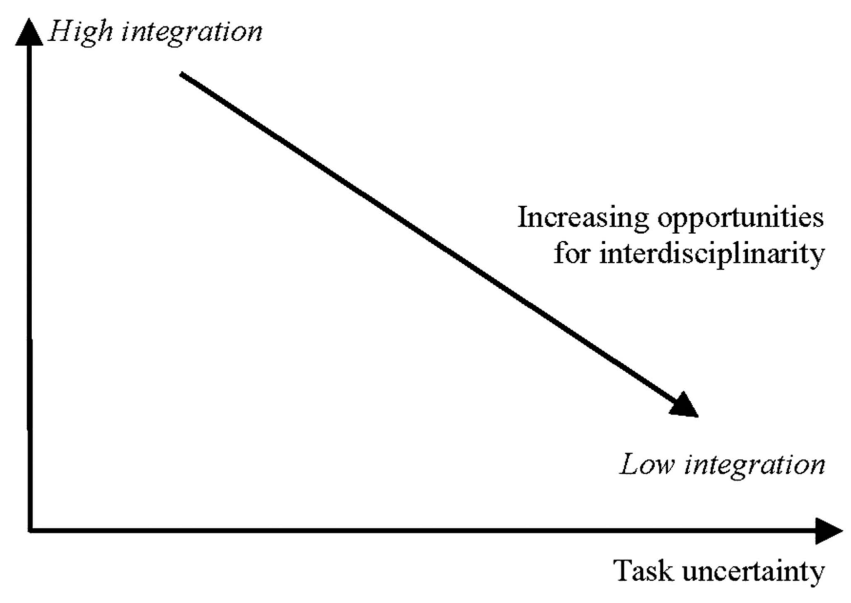

Figure 3. The integration of scientific fields.

high degrees of freedom to choose what to do and how to do it. ${ }^{11}$ In terms of interdisciplinarity, Figure 3 points to the fact that the opportunities for such research increase as integration decreases. Or, in other words, regarding the obstacles for interdisciplinarity: the higher the integration of a scientific field, the lower the propensity for researchers in the field to engage in interdisciplinary research and vice versa.

\section{Institutions}

A second important condition for interdisciplinarity is associated with the organizational structure in which the research is undertaken. Here, a basic distinction can be made between, on the one hand, research institutes and, on the other hand, universities. The basic difference between the two is obviously that research institutes are oriented solely towards research. There are no students to teach and no need to coordinate teaching with representatives of other disciplines. As a result, researchers in research institutes can focus more on their research projects in a programmeoriented organization with problem-oriented recruitment. This in turn provides greater opportunities for interdisciplinary research.

As far as universities are concerned, the idea of Wilhelm von Humboldt that teaching and research should go hand in hand has been widely accepted, although with variations across countries. Strangely enough, Humboldt's idea is not fully practised in his home country, where the Max Planck Institutes and the Frauenhofer Institutes constitute important parts of the research infrastructure. ${ }^{12}$ However, some other countries, such as Sweden, strongly subscribe to the Humboldt principles of combining teaching and research. This is also the case in top US universities, where faculty members are expected to contribute equally to teaching, research and service to their institution. ${ }^{13}$ 
European universities are typically organized by discipline into departments. This means that recruitment is effectively based on disciplinary competence (see further below). Another effect is that representatives of these departments compete for internal resources and prestige. This competition is likely to negatively impact interdisciplinary cooperation. However, a counterbalancing factor may be educational programmes that require cooperation among different departments.

Although US universities also have departmental structures, to a considerable extent they have research institutes inside them as well as professional schools: medical schools, law schools, business schools, etc. In this way, these programme-oriented organizations tend to feature interdisciplinary recruitment. A prime example, in terms of professional schools, is constituted by US business schools since the 1960s. After complaints about the low academic standards in such institutions, both the Carnegie Corporation and the Ford Foundation commissioned studies to improve US business education. They published their reports in 1959, both concluding that more academically qualified faculty members had to be recruited. ${ }^{14}$ As a result, US business schools in the 1960s started the recruitment of faculty members from a variety of disciplines, particularly in the social sciences: political scientists, psychologists, sociologists, statisticians, etc., but also mathematicians. In this way, the business schools became interdisciplinary organizations. It is also worth noting that from the very outset, at the beginning of the twentieth century, US universities were more inclined to include business education, while the more strongly discipline-organized European universities kept them outside and forced them to start as standalone institutions. ${ }^{15}$

From the above we can conclude that the organization of teaching and research is important for the opportunities for interdisciplinarity. Obviously, research institutes outside universities may provide opportunities for interdisciplinary research, but that can also be the case inside universities if they are not strictly organized into disciplinary departments or if such departments have to collaborate in specific programmes. To conclude on the obstacles for interdisciplinarity: the higher degree of disciplinary organization, the lower the propensity of researchers to engage in interdisciplinarity, and vice versa.

\section{Quality Control}

As far as quality control is concerned, there are two basic mechanisms in academia: input control and output control. The first refers to the procedures for hiring researchers and faculty members, while the second has to do with the evaluation of their performance. Whereas the input control is a basic and traditional mechanism of scientific fields with insiders assessing whether applicants are worthy of being hired, output control has greatly increased in importance during the past few decades. Citation counts, impact factors, and the H-index are tools that have particularly gained in importance.

In terms of the input control, two fundamental principles can be identified: the bureaucratic model and the task-oriented model. The former is based on the idea that hiring of faculty is constituted by an open global competition among highly qualified 
scholars in a particular scientific field. In addition, it postulates that candidates are evaluated by means of objective criteria by selected peers. In this way, it is assumed that the most qualified candidate will be selected. In principle, peers are not expected to take into consideration the research environment where the person is going to be active. It is exclusively the candidates' competence in the specific discipline as described in the job posting that should be considered. This model is particularly practised in government-funded European universities.

The task-oriented model, on the other hand, is based on the wish to recruit persons who have a particular competence to contribute to a specific research task. Thus, in this case, the hiring institution is not looking for persons who are the most competent on the basis of general criteria of competence within a discipline but those who will be best at handling and solving specific problems. While the bureaucratic model is more associated with public administration, the task-oriented model is related to market solutions. Needless to say, it is the main principle used in corporations. In the context of research, it is used in research institutes (see above) and among universities it is particularly common among US private institutions. There can be no doubt that the taskoriented recruitment model hampers interdisciplinary research to a lesser extent than the bureaucratic model.

As mentioned, the output control is the mechanism for evaluating the production of researchers. There is considerable evidence that this control has increasingly become focused on publishing in high-prestige journals with high impact factors. ${ }^{16}$ Since these tend to be discipline-oriented, strong output control may make it difficult to publish interdisciplinary research. ${ }^{17}$ We can identify two mechanisms behind this. First, individual journals tend to be normalized over time within their disciplines, since prospective submitters of papers look at the previous papers to judge what the journal considers fit to print. As a result, there is self-selection already at the submission stage. This tendency is then reinforced by the second mechanism, which is the peer-review process. Fully in accordance with the ideas of Thomas Kuhn, the selected reviewers, who are insiders to the specific scientific field, can be expected to reject papers that deviate too much from those normally published. Since interdisciplinary research is likely to be different, output from such research runs a high risk of being rejected.

Together, the input and output controls in academia thus play significant roles for the possibilities of undertaking interdisciplinary research. Formal models for recruitment, the bureaucratic model, and metrics in terms of performance may discourage interdisciplinary research. In other words: the higher the degree of disciplinary quality control, the lower the propensity of researchers to engage in interdisciplinary research, and vice versa.

\section{Funding}

Two basic modes can be identified also with respect to funding, namely (1) block grants to institutions, and (2) project funding granted to research groups or researchers on the basis of applications. Of these, the first is the basic funding 
mechanism for research institutes and has also been the traditional funding mechanism for universities.

Originally, project grants constituted supplements to block grants. They were provided by private foundations such as the Rockefeller Foundation (founded in 1913) and the Ford Foundation (founded in 1936) in the United States, the Wellcome Trust (founded in 1936) in the United Kingdom, the Knut and Alice Wallenberg Foundation (founded in 1917) in Sweden, and the Volkswagen Stiftung (founded in 1961) in Germany. ${ }^{18}$ The twentieth century also saw the creation of a number of public research-funding bodies, such as the Medical Research Council (founded in 1913) in the United Kingdom, Deutsche Forschungsgemeinschaft (first founded in 1920) in Germany, and the National Science Foundation (founded in 1950) in the United States. ${ }^{19}$ Their examples were followed in many countries. More recently, private foundations have increased in number, and some of them, such as the Bill \& Melinda Gates Foundation (founded in 2000), have spectacular capacity for funding. At the same time, there have also been ambitions by governments to allocate research resources in order to solve specific problems in society. In relation to the discussion above, this has implied an increasing specification of tasks to be accomplished. This is in line with the arguments regarding the new production of knowledge, i.e. moving from Mode I (basic research) to Mode II (applied research), and the application of the Triple Helix model, i.e. the interaction between academia, government, and industry. ${ }^{7}$ In Europe, this has been manifested through the Framework Programmes and in individual countries by special funds being channelled either directly from the central government or through special research councils. However, with the passage of time, resource allocation has become increasingly based on strictly scientific criteria. A prime example is the creation of the European Research Council (founded in 2007), which has now become the ultimate quality stamp for researchers. ${ }^{20}$ This in turn has produced a Matthew Effect, i.e. that research funds are concentrated in the hands a limited number of established researchers. ${ }^{21}$

The above means that governments are increasingly channelling research funding through project financing rather than block grants. One explanation for this is the general tendency in modern societies, since the 1980s, to introduce market models in various sectors, academia included. ${ }^{22}$ Another reason is the expansion of national systems for higher education and research, leading to increasing difficulties in establishing priorities among a large number of academic institutions. In this way, the writing of applications for research grants has become a significant task of academics. Success rates have tended to decline, and the harsh competition has even led some governments and university leaders to use external grants as an indicator for the allocation of block grants. Needless to say, this is another example of the Matthew Effect mentioned above.

Interestingly, in times when the corporate line-management model, with demands on university leaders to act strategically, is spreading to universities, the increasing share of project financing has had the effect that the control of these leaders over the institutional cash flow is reduced. Funding does not go through the central administration but rather directly to the research groups and the individual researchers. 
This is of course irritating for university leaders but might nevertheless be good for creativity, including interdisciplinary research.

The above implies that the sources for research funding have multiplied. This in turn should be seen as good for interdisciplinary research, since researchers have a larger number of opportunities to seek funding. However, as mentioned above, it should also be noted that the funding organizations need legitimacy and thereby tend to recruit well-reputed representatives from the established disciplines to set the priorities. This in turn may hamper the willingness to fund interdisciplinary research. Thus, to summarize the obstacles for interdisciplinary research in relation to funding: the higher the concentration of funding sources and power of established disciplines, the fewer the opportunities for interdisciplinarity, and vice versa.

\section{Conclusions}

Focusing on the structural conditions for interdisciplinarity this paper has pointed to the significance of disciplines, institutions, quality control and funding (Figure 1). As shown in Figure 4 it has been found that all four may hamper interdisciplinarity.

First, for disciplines (left-hand box) it has been argued that the higher the integration within a scientific field, the lower the propensity for researchers in the field to engage in interdisciplinary research, and vice versa. A highly integrated field is understood here as one where the researchers face low task uncertainty and high dependence among researchers. In terms of task uncertainty, these are fields where there is a level of high certainty about the problems to solve and the approaches to finding the solutions. This high certainty is then also reinforced by a strong dependence among field members. Another way to express the latter is that scientific elites control the field.

Second, for institutions (upper box in Figure 4) it has been argued that the higher the degree of disciplinary organization, the lower the propensity will be for researchers to engage in interdisciplinary research, and vice versa. In other words, the more a research organization is structured according to academic disciplines, the more likely it is that department members will 'stick to the knitting' and abstain from moving into collaboration with colleagues in other disciplines. Obviously, this

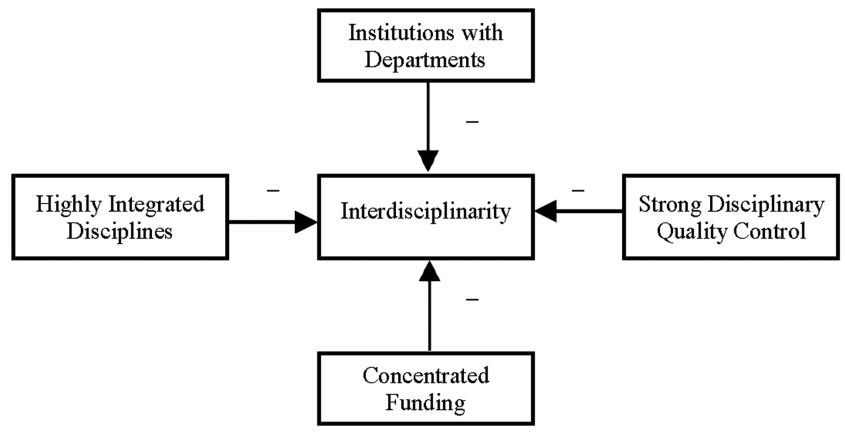

Figure 4. Obstacles to interdisciplinarity 
tendency is related to the above-discussed integration of scientific disciplines. Thus, a high degree of integration of a particular discipline in a research organization with departments will make the obstacles towards interdisciplinarity even stronger.

Third, for quality control (right-hand box in Figure 4), it has been pointed out that the higher the degree of disciplinary quality control, the lower the propensity of researchers in the field to engage in interdisciplinary research, and vice versa. This factor is particularly related to the criteria used for hiring faculty and for promotion. This factor is also related to the integration of a particular scientific field, since higher integration means a more advanced disciplinary organization with professional meetings and recognized journals. Thus, in highly integrated scientific fields we can expect that the pecking order of journals will be more entrenched, and that top journals in the field are those exclusively acknowledged in relation to hiring and promotion decisions. However, these decisions are also related to institutional arrangements, i.e. institutions organized according to principles other than the departmental principle can be expected to be more open to interdisciplinarity.

Fourth, for funding (lower box in Figure 4) it has been pointed out that the traditional block grants to institutions have, to a large extent, been replaced by project grants. This has happened through the emergence and growth of a population of private foundations as well as through shifts in government funding systems towards project financing. Together, these developments have implied an increased variety of research funding, which can be considered a positive factor for interdisciplinarity. However, this has to a great extent been hampered by a tendency of funding organizations to recruit well-reputed representatives of established disciplines to guide allocation decisions. This, in turn, can be expected to hamper interdisciplinarity. Again, there are reasons to point to the significance of disciplinary integration, i.e. that the more representatives in the allocation of decisions come from disciplines with high integration, the greater the difficulties for interdisciplinary projects. Thus: the higher the concentration of funding sources and power of established disciplines, the lower the opportunities for interdisciplinarity, and vice versa.

In sum, the above means that interdisciplinarity can be expected to be less likely when (1) disciplines are highly integrated; (2) institutions have distinct departmental structures; (3) quality control is strongly based on disciplinary criteria; and (4) funding is highly concentrated. These four factors may also reinforce each other to the disadvantage of interdisciplinarity.

Having so far focused on the hampering of interdisciplinary research, it is appropriate to also point to conditions that can be expected to facilitate interdisciplinarity. An obvious first step is then to turn the previous paragraph around. This means that we can expect participation in interdisciplinary research to be more likely among researchers from disciplines characterized by low integration and working in institutions with cross-disciplinary structures. It is also more likely when quality control is weakly based on disciplinary criteria and when funding systems permit nonmainstream research.

However, even if these positive circumstances are present, it is important for interdisciplinary research that researchers from different disciplines get in touch with 
each other. One important way for this to happen is by interdisciplinary educational programmes, which means that representatives from different disciplines have to work together. Within universities it is also important to mention opportunities for interdisciplinary interaction, such as University Senates and Faculty Clubs. Outside universities and research institutes it is also appropriate to mention learned societies, where academics can meet without too much competition for resources. However, as pointed out above, it appears that international exchange is the most important force for interdisciplinarity. International conferences and international cooperation are significant for the breaking up of traditional national or local structures. Last, but not least, extra resources, be they national or international, are often the key to innovative interdisciplinary research. At the same time, it has to be acknowledged that interdisciplinary research is not an end in itself but rather a means for solving problems that require interdisciplinary competence.

\section{References and Notes}

1. Among earlier works on interdisciplinarity, see for example J.T. Klein (1990) Interdisciplinarity: History, Theory, and Practice (Detroit: Wayne State University Press); J.T. Klein (2005) Humanities, Culture, and Interdisciplinarity: The Changing American Academy (Albany, NY: State University of New York Press); and J.H. Aldrich (2014) Interdisciplinarity (Oxford: Oxford University Press).

2. Facilitating Interdisciplinary Research (2004) (Washington, DC: National Academies Press), p. 2.

3. The Concise Oxford Dictionary of Current English, 7th edn (1982) Edited by J.B. Sykes (Oxford: Oxford University Press), p. 273.

4. R.K. Merton (1965) On the Shoulders of Giants (New York: Free Press).

5. T.S. Kuhn (1962) The Structure of Scientific Revolutions (Chicago: University of Chicago Press).

6. S. Fuller (2000) Thomas Kuhn: A Philosophical History for Our Times (Chicago: Chicago University Press).

7. M. Gibbons, C. Limoges, H. Nowotny, S. Schwartzman, P. Scott and M. Trow (1994) The New Production of Knowledge: The Dynamics of Science and Research in Contemporary Societies (London: Sage); H. Nowotny, P. Scott and M. Gibbons (2001) Re-Thinking Science: Knowledge and the Public in an Age of Uncertainty (Cambridge: Polity Press); and H. Etzkowitz (2008) The Triple Helix: University-Industry-Government Innovation in Action (London: Routledge).

8. C.E. Lindblom (1959) The science of 'muddling through'. Public Administration Review, 19(2), pp. 79-88.

9. L. Engwall and T. Hedmo (2016) The organizing of scientific fields: the case of corpus linguistics. European Review, 24(4), pp. 568-591. For an analysis of the insider-outsider problem, see A. Lindbeck and D.J. Snower (1988) The InsiderOutsider Theory of Employment and Unemployment (Cambridge, MA: MIT Press).

10. R. Whitley (1984) The Intellectual and Social Organization of the Sciences (Oxford: Oxford University Press, 2nd edn 2000).

11. For an empirical test, see L. Engwall (1995) Management research: a fragmented adhocracy? Scandinavian Journal of Management, 11(3), pp. 225-235. 
12. L. Engwall and I. Lindqvist (1990) Forschung in der Bundesrepublik Deutschland - aus schwedisher Sicht. Futura, 5(3), pp. 13-18.

13. L. Engwall (2018) Montesquieu in the university: the governance of world-class institutions of higher education and research. European Review, 26(2), pp. 285-298.

14. F.C. Pierson (1959) The Education of American Businessmen (New York: McGraw-Hill), and R.A. Gordon and J.E Howell (1959) Higher Education for Business (New York: Columbia University Press).

15. L. Engwall, M. Kipping and B. Üsdiken (2010) Public science systems, higher education, and the trajectory of academic disciplines: business studies in the United States and Europe. In: R. Whitley, J. Gläser and L. Engwall (Eds), Reconfiguring Knowledge Production: Changing Authority Relationships in the Sciences and their Consequences for Intellectual Innovation (Oxford: Oxford University Press), pp. 325-353.

16. See the contributions in W. Blockmans, L. Engwall and D. Weaire (Eds) (2014) Bibliometrics: Use and Abuse in the Review of Performance (London: Portland Press).

17. This in turn appears to be reinforced by rankings. See I. Rafols, L. Leydesdorff, A. O'Hare, P. Nightingale and A. Stirling (2012) How journal rankings can suppress interdisciplinarity: the case of innovation studies in business and management. Research Policy, 41(7), pp. 1262-1282.

18. https://www.rockefellerfoundation.org/about-us/our-history/, https://www. fordfoundation.org/about-us/our-origins/, https://wellcome.ac.uk/about-us/historywellcome (accessed 24 July 2017); C. Dahlberg (Ed.) (2017) Knut och Alice Wallenbergs stiftelse: 100 år av stöd till excellent svensk forskning och utbildning (The Knut and Alice Wallenberg Foundation: 100 Years of Support to Excellent Swedish Research and Education) (Stockholm: Max Ström); and https://www.volkswagenstiftung.de/en/foundation/history.html (accessed 24 July 2017). For the role of foundations for interdisciplinary research, see J.H. Aldrich (2014) Interdisciplinarity (Oxford: Oxford University Press), Chapters 5-8.

19. https://www.mrc.ac.uk/about/what-we-do/history/, http://www.dfg.de/en/ dfg_profile/history/dfg_origins/index.jsp and https://www.nsf.gov/about/history/ nsf50/nsf8816.jsp\#chapter1 (accessed 24 July 2017).

$20 \mathrm{https} / / /$ rec.europa.eu/projects-figures/facts-and-figures (accessed 24 July 2017).

21. See P. Edlund (2018) Constructing an Arbiter of Status: A Study of the European Research Council's Emergence in the Field of Science, doctoral dissertation from the Department of Business Studies, Uppsala University.

22. See for example D.C. Bok (2003) Universities in the Marketplace: The Commercialization of Higher Education (Princeton, NJ: Princeton University Press); and L. Engwall and D. Weaire (Eds) (2008) The University in the Market (London: Portland Press).

\section{About the Author}

Lars Engwall is professor emeritus of management at Uppsala University, Sweden. His research has been particularly directed toward the production and diffusion of management knowledge. Among his recent publications are From Books to MOOCs? (2016, edited with Erik De Corte and Ulrich Teichler, Portland Press), Defining Management (2016 with Matthias Kipping and Behlül Üsdiken, Routledge) and Corporate Governance in Action (ed. 2018, Routledge). He is an elected member of a number of learned societies and has received honorary degrees from Åbo Akademi University and the Stockholm School of Economics. 